\title{
Boron Neutron Capture Therapy for Cancer: Future Prospects in Indonesia
}

\author{
Bagaswoto Poedjomartono ${ }^{1,3,{ }^{*}}$, Hanif Afkari ${ }^{1}$, Edy Meiyanto ${ }^{2}$, Alan Bangun ${ }^{3,4}$, and Yohanes Sardjono ${ }^{5}$ \\ ${ }^{1}$ Department of Radiology, Radionuclear Services, Faculty of Medicine, Public Health, and Nursing, Universitas Gadjah Mada, \\ Yogyakarta 55281, Indonesia \\ ${ }^{2}$ Faculty of Pharmacy, Universitas Gajah Mada, Jalan Sekip Utara, Sendowo, Yogyakarta 55281, Indonesia \\ ${ }^{3}$ Dr. Sardjito General Hospital, Jalan Kesehatan No. 1, Yogyakarta 55281, Indonesia \\ ${ }^{4}$ Faculty of Medicine, Diponegoro University, Semarang 50275, Indonesia \\ ${ }^{5}$ Center of Accelerator Science and Technology, National Nuclear Energy Agency, Yogyakarta 55281, Indonesia \\ *Corresponding author: bagaswoto.poedjomartono@ugm.ac.id
}

KEYWORDS

BNCT

Cancer

PGB-0

Targeting therapy
ABSTRACT Boron neutron capture therapy (BNCT) is a form of cancer therapy based on the interaction of low-energy thermal neutrons and boron-10 (10-B) to produce alpha radiation from $\mathrm{He}-4$ and $\mathrm{Li}-7$ with a high linear energy transfer. A beam of neutrons irradiates a boron drug injected into the tumor, resulting in the boron-injected cancer cells receiving a lethal dose of radiation with the surrounding, healthy cells being minimally affected. Two boron drugs have been used clinically in BNCT, boron sodium captate (BSH) and borophenylalanine (BPA), while a third, pentagamaboronon-0 (PGB-0), is currently under development in the Faculty of Pharmacy of Universitas Gadjah Mada, Indonesia. In Indonesia, there has been a growing interest in the study and use of BNCT to treat cancer, as this method is expected to be safer and more effective than traditional cancer treatment methods.

(c) The Author(s) 2018. This article is distributed under a Creative Commons Attribution-ShareAlike 4.0 International license.

\section{INTRODUCTION}

The ideal cancer therapy is one that is non-invasive, can kill cancer cells specifically without damaging normal cells around them, and does not have severe side effects. At present, cancer therapy comprises surgical procedures, chemotherapy, radiotherapy, or a combination thereof. These three types of cancer therapies, however, are known to have significant side effects. Therefore, a more effective method of treating cancer needs to be developed. One such method is boron neutron capture therapy, or BNCT. BNCT is a nuclear reaction based therapy that occurs when 10$\mathrm{B}$ is irradiated with low-energy neutrons to produce highenergy alpha particles from helium $(\mathrm{He}-4)$ and lithium (Li7). With regards to cancer, BNCT has more advantages than chemotherapy. The administration of chemotherapy drugs results only in killing cancer cells that are actively dividing, whereas alpha particles have the ability to damage tumor cells that are not dividing (Barth et al. 1990). These alpha particles have a very short range, only 9-14 $\mu \mathrm{m}$, while the cell size is between 10 and $20 \mu \mathrm{m}$. Therefore, the radiation only occurs within the tumor cells, and the normal cells surrounding the tumor site are consequently relatively safe (Barth et al. 1990).

In the treatment of brain tumors, BNCT therapy is carried out by injecting $10-\mathrm{B}$ with boron sodium captate (BSH) or intravenous borophenylalanine (BPA) to localize the tumor. In Indonesia, a new boron drug, pentagamaboronon0 (PGB-0) is currently under development in the Faculty of Pharmacy, Universitas Gadjah Mada, in which 10-B is mixed with curcumin analogues to be used for breast cancer therapy with positive molecular markers of HER2.

\section{CANCER}

In 2012, there were approximately 8.2 million deaths caused by cancer, among which lung cancer, liver cancer, pancreas cancer, colorectal cancer, and breast cancer were the most prevalent. Smoking is a main risk factor to cancer, while other risk factors include a high body mass index (BMI), lack of consumption of fruits and vegetables, inactivity, and excessive consumption of alcohol. It is estimated that the annual number of cancer cases will increase from 14 million in 2012 to 22 million within the next two decades (Ministry of Health 2016).

Based on GLOBOCAN (IARC) in 2012, breast cancer had the largest percentage of new cases, at $43.3 \%, 12.9 \%$ of which were fatal. Meanwhile, lung cancer was the type of cancer with the highest number of new cases and was the leading cause of death in male populations. However, lung cancer also had a high percentage in female populations, at $13.6 \%$, with a mortality rate of $11.1 \%$. Liver cancer had a relatively equal percentage of mortality in both male and female populations. Breast cancer and prostate cancer had a much lower percentage of deaths than the percentage of new cases, suggesting that if these forms of cancer can be detected and treated early the chances of recovery will be higher (IARC 2013). Based on pathology-based registration, the relative incidence of breast cancer reached 11-12 new cases per 100,000, at-risk population (Manuaba 2010; Wahidin et al. 2012; WHO 2014). Indonesia, in 2013, had a prevalence of cancer among all ages of $1.4 \%$ o, or an estimated 347,792 people. The Special Region of Yogyakarta in Java island had the highest incidence of cancer in Indonesia in 2013 , at $4.1 \%$ with the estimated absolute number 
of 14,596 people (NIHRD 2003). Cervical and breast cancer had the highest prevalence, with $0.8 \%$ ond $0.5 \%$, respectively. Specifically in Yogyakarta, where the highest incidence of cancer was found, the prevalence of cervical cancer was $1.5 \%$, and $2.4 \%$ o for breast cancer.

\section{BORON NEUTRON CAPTURE THERAPY}

BNCT was introduced in the $1960 \mathrm{~s}$, but showed little progression, because the thermal and epithermal neutron sources were not economical. Nuclear reactor, with a cyclotron was used recently as a source of neutrons, thus enabling the usage widely (Barth et al. 1990). Gamma rays are used to irradiate tumor tissue, and fractional doses of up to 50-60 Gray are needed for tumor ablation in conventional radiation therapy. This high dose of radiation not only damages the tumor cells but also harms the surrounding normal tissues. BNCT is intended to eliminate side effects from conventional radiation therapy. Basically, BNCT internalize 10-boron into the tumor which is irradiated by 1 neutron, resulting in the insertion of 7 lithium and 4 alpha particles into the tumor cell which has lethal energy to kill the tumor specifically $(10-\mathrm{B}+1 \mathrm{n} \rightarrow 7 \mathrm{Li}+4 \mathrm{He}+2.31 \mathrm{MeV}$ (93.7\%) or $10-\mathrm{B}+1 \mathrm{n} \rightarrow 7 \mathrm{Li}+4 \mathrm{He}+2.79 \mathrm{MeV}(6.3 \%))$. The ions and particles of lithium are particles with high linear energy transfer (LET), which produces a considerable biological effect.

BNCT is a two-component modality, where the enriched 10-B compounds are given before irradiated with thermal neutron rays. The 10-B absorbs neutrons and releases alpha particles from the nucleus $(4 \mathrm{He})$ and lithium (7Li). Because this product has the reach only 5-10 $\mu \mathrm{m}$ in water, the effect depends on maintaining a relatively high 10 - $\mathrm{B}$ concentration in the tumor compared to the surrounding normal tissue. Only tumor cells that absorb 10-B are destroyed.

The short range of alpha particles in the tissue (5$10 \mu \mathrm{m})$ limits cell damage, because radiation only occurs in cells that absorb boron atoms (Yanagie et al. 2009). Borophenylalanine, boron sodium captate, and the molecule used by our team, namely BoronoDeoxy-DGlucose (BDG), are used to target boron into tumor tissue. BNCT is primarily intended to be used for the treatment of neck and head cancers due to technical difficulties and economic burden. However, the recent technical improvements in BNCT applications have led to this technique being considered for the treatment of soft tissue tumors such as breast cancer (Akan et al. 2014).

Breast cancer is the most commonly diagnosed cancer in women. Recurrent breast cancer (RBC) is potentially lifethreatening. Even though radiation therapy is common to do, this therapy has several side effects and is not potent enough to be used in RBC patients. Recently, BNCT is introduced in the medical field as an alternative treatment for cancer. The successes in in-vitro studies and simulations have led scientists to prepare successful clinical outcomes in the future (Menichetti et al. 2009; Horiguchi et al. 2011). To maximize the potency of BNCT, it requires a proper combination of thermal/epithermal neutron fluctuation which is related to the selective boron intake in target tissue. With the new boron carrier design and neutron source, BNCT can play an important role in treating this malignancy, either primary or recurrence cancer, because until now there has been no effective therapy to treat cancer.

\section{CHEMOTHERAPY'S ADVERSE EFFECTS}

Chemotherapy is the process of inserting drugs through veins into the body. This method makes the level of drug concentration in the center of the tumor and other tissues the same. Thus, chemotherapy can damage a variety of healthy organs, not just diseased body tissues. It causes some side effects such as; decreased of leukocytes and platelets, hematuria, decreased body immune cells, hair loss in most patients, etc.

Cancer cells tend to grow fast, and chemo drugs kill fast-growing cells. However, since these drugs spread throughout the body, they can also affect the fast growing normal and healthy cells. The damage to the healthy cells causes side effects. Some chemo drugs cause long-term side effects, such as heart or nerve damages and also fertility problems. Yet, there are also many people who do not have long-term problems from chemo. The side effects of chemo have to be considered to need to kill cancer cells. Normal cells that are most likely damaged by chemo are:the blood-forming cells in the bone marrow, hair follicles, cells in the oral cavity, the gastrointestinal tract, and reproduction system.

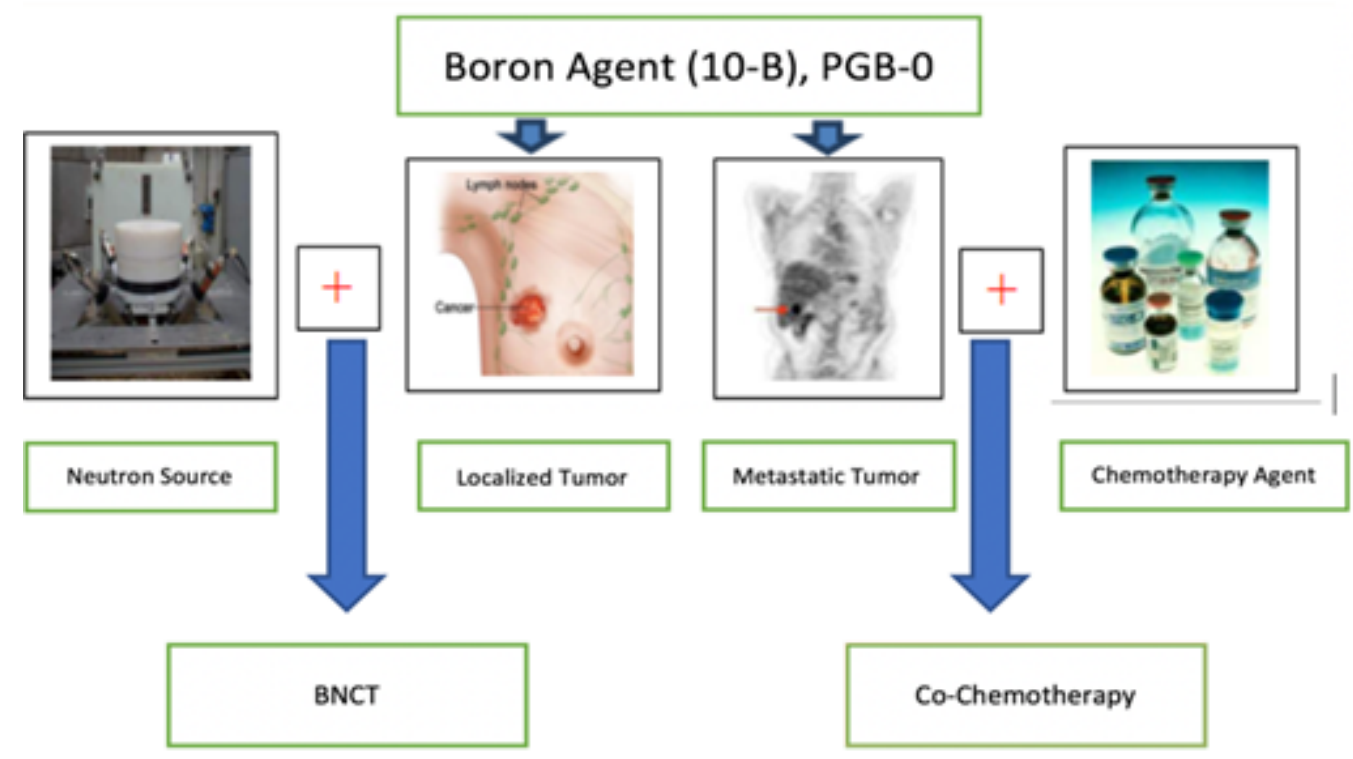

FIGURE 1. The Application of PGB-0 in BNCT and co-chemotherapy agent. 
Some drugs can damage the cells of the heart, kidneys, bladder, lungs, and nervous system. Sometimes, other drugs are administered alongside chemotherapy drugs to protect the healthy or normal body cells. There are also treatments to help alleviate side effects. Generally, doctors try to administer the chemo at a high enough level to treat cancer while maintaining minimal side effects. They also try to avoid the use of drugs that have similar side effects (American Cancer Society 2016).

Many side effects disappear quickly, but some may take months or even years to completely disappear. Sometimes side effects can last a lifetime, such as when chemo causes a long-term damage to the heart, lungs, kidneys, or reproductive organs. Certain types of chemotherapy sometimes cause delayed effects, such as a second cancer that may appear years later. The time taken to overcome some side effects and regain the energy varies to each person and it depends on many factors, including health status and current medication.

\section{DISCUSSION}

Indonesia is now developing PGB-0, which is a $10-\mathrm{B}$ that is mixed with a curcuma analogue for use in cancer therapy. Based on GLOBOCAN (IARC) 2012, breast cancer had the highest percentage of new cases among all kinds of cancers, namely $43.3 \%$ with a mortality rate of $12.9 \%$. If the cancer can be detected early it will lead to a better recovery process (IARC 2013). Yogyakarta had the highest cancer prevalence $(4.1 \%$ ) with an estimated absolute number of 14,596 people. Cervical and breast cancer had the highest prevalence in Indonesia in 2013, $0.8 \%$ o and $0.5 \%$, respectively, with the highest prevalence of these cancers being found in Yogyakarta-1.5\%o and 2.4\%o, respectively (NIHRD 2003).

The new concept of BNCT, which is a radiation binary targeted for cancer treatment, consists of a combination of two approaches that have never been used in the previous synergism. This combination brings realistic hopes to patients with recurrence or metastatic cancer. This therapy assumes that anti-HER2 Monoclonal Antibody Boronas (MABs) is given to patients and accumulated in tumor. Then the tumor is destroyed when exposed to neutron irradiation. Because the use of anti-HER2 MAB shows good and promising results, the concept of BNCT is expected to strengthen the therapeutic effect. It can be the most likely additional treatment for patients with severe breast cancer, the patient with metastatic cancer who is failed to show improvement with another treatment method, and patients who refuse the standard treatment protocol.

The complexity of cancer causes many types of proteins that play a role in the growth and malignancy of cancer cells. One biomarker of cancer that is widely used as a therapeutic target is HER2. This compound has been proved to have the ability to interact with cancer markers specifically and has a significant effect in the treatment of cancer. Pentagamaboronon-0 (PGB-0) is an analogue of curcumin that has the same therapeutic effect as curcumin, which shows an inhibition of cancer cells that express the HER2 protein (cellMCF-7/HER2). This curcumin analogue is still under development in Indonesia. The combination of PGB- 0 and a chemotherapy agent is known to inhibit the migration of metastatic breast cancer cells. It is hoped that PGB-0 will have several ways of developments, one as a 10-B delivery agent in BNCT and another as a cochemotherapy, as described in Figure 1.

A potential increase in the therapeutic ratio of subcellular boron bio distribution is showed on micro dosimetry examination. Clinical case studies of technique simulation show the advantages of using BNCT for the treatment of breast cancer with positive HER2. BNCT is a cell targeted therapy that kills only specific cancer cells, and as such has relatively no adverse effects.

\section{CONCLUSIONS}

BNCT brings new hope to cancer patients in Indonesia, especially those with breast cancer. It is expected that with PGB-0, it will soon be easier to carry out therapy with BNCT, particularly in Indonesia, where cancer patients await an effective treatment method that can accurately treat the cancer while at the same time minimizing harm to the rest of the body.

\section{REFERENCES}

Akan Z, Demiroglu H, Avcibasi U, Oto G, Ozdemir H, Deniz S, Basak AS. 2014. Complexion of boric acid with 2-deoxyd-glucose (DG) as a novel boron carrier for BNCT. Med Sci Discovery. 1(3):65. doi:10.17546/msd.74442.

American Cancer Society. 2016. Chemotherapy side effects. https://www.cancer.org/treatment/treatments-an d-side-effects/treatment-types/chemotherapy/ch emotherapy-side-effects.html.

Barth RF, Soloway AH, Fairchild RG. 1990. Boron neutron capture therapy of cancer. Cancer Res. 50(4):1061-1070.

Horiguchi H, Nakamura T, Kumada H, Yanagie H, Suzuki M, Sagawa H. 2011. Investigation of irradiation conditions for recurrent breast cancer in JRR-4. Appl Radiat Isot. 69(12):1882-1884. doi:10.1016/j.apradiso.2011.03.036.

[IARC] The International Agency for Research on Cancer. 2013. Latest world cancer statistics - Global cancer burden rises to 14.1 million new cases in 2012: Marked increase in breast cancers must be addressed. Press release No. 223.

Manuaba I, editor. 2010. Panduan Penatalaksanaan Kanker Solid PERABOI 2010. Jakarta: Sagung Seto.

Menichetti L, Gaetano L, Zampolli A, Del Turco S, Ferrari C, Bortolussi S, Stella S, Altieri S, Salvadori P, Cionini L. 2009. In vitro neutron irradiation of glioma and endothelial cultured cells. Appl Radiat Isot. 67(7-8):S336S340. doi:10.1016/j.apradiso.2009.03.058.

Ministry of Health. 2016. Profil kesehatan Indonesia tahun 2015 [Indonesia's health statistics 2015]. Technical report. Ministry of Health Republic of Indonesia. http: //www.depkes.go.id/resources/download/general/ Hasil\%20Riskesdas\%202013.pdf.

[NIHRD] National Institute of Health Research and Development. 2013. Riset kesehatan dasar [Basic health research]. Technical report. Ministry of Health Republic of Indonesia. http://www.depkes.go.id/resources/d ownload/general/Hasil\%20Riskesdas\%202013.pdf.

Wahidin M, Noviani R, Hermawan S, Andriani V, Ardian A, Djarir H. 2012. Population-based cancer registration in Indonesia. Asian Pac J Cancer Prev. 13(4):1709-1710. doi: 10.7314/APJCP.2012.13.4.1709.

[WHO] World Health Organization. 2014. WHO - Cancer country profiles Indonesia 2014. Geneva: World Health Organization.

Yanagie H, Kumada H, Sakurai Y, Nakamura T, Furuya Y, Sugiyama H, Ono K, Takamoto S, Eriguchi M, Takahashi H. 2009. Dosimetric evaluation of neutron capture therapy for local advanced breast cancer. Appl Radiat Isot. 67(7-8):S63-S66. doi:10.1016/j.apradiso.2009.03.1 10. 